\title{
A Guide for the Cultivation of Onion under Controlled Environment Conditions
}

\author{
Jiffinvir Khosa and Robyn Lee \\ Department of Biochemistry, University of Otago, 710 Cumberland Street, \\ Dunedin 9054, New Zealand
}

\section{Srishti Joshi}

Bioprocess and Bioseparations Laboratory, Department of Chemical Engineering, Indian Institute of Technology, New Delhi 110016, India

Martin Shaw

Plant and Food Research, Gerald Street, Lincoln 7608, New Zealand

John McCallum ${ }^{1}$

Department of Biochemistry, University of Otago, 710 Cumberland Street, Dunedin 9054, New Zealand; and Plant and Food Research, Gerald Street, Lincoln 7608, New Zealand

\author{
Richard Macknight ${ }^{1}$ \\ Department of Biochemistry, University of Otago, 710 Cumberland Street, \\ Dunedin 9054, New Zealand
}

Additional index words. growth conditions, photoperiod, light quality, sciarid fly

\begin{abstract}
Bulb onion (Allium cepa $\mathbf{L}$.) is a challenging subject for experimental studies because of its slow growth, genetic heterogeneity, and sensitivity to environmental and biotic stresses. Sharing of common germplasm and controlled propagation practices has underpinned research on model plants, such as Arabidopsis and tomato, but not in onion. To encourage wider evaluation of onion for physiological and molecular studies in controlled environments, we describe the growing practices we have developed over two decades of research on adaptive and nutrient assimilation traits. Key aspects covered include choice of germplasm, propagation media, nutrition, and environmental control. Adopting common onion genetics and cultivation techniques across laboratories will allow researchers to answer deeper research questions and increase the reproducibility of the research.
\end{abstract}

Onion and shallot (Allium cepa L.) are cultivated in a wide range of environments, from hot equatorial regions to high latitudes. Although onion has great cultural and economic value, experimental studies involving genetics and agronomy are quite limited because of the practical challenges it poses as an experimental subject. General agronomic practices have been reviewed by Serra and Currah (2002) and a number of extension manuals are available that describe production technology for outdoor cultivation (Brewster, 2008); however, these are intended for farmers and extension workers rather than researchers wishing to grow onions under controlled environmental conditions for experimental purposes. Historically, research publications

Received for publication 22 Aug. 2018. Accepted for publication 15 Oct. 2018 .

This research was funded by the New Zealand Ministry of Business, Innovation and Employment. We thank Cara Norling and Stephen Trolove (Plant and Food Research) for helpful feedback on this manuscript.

${ }^{1}$ Corresponding authors. E-mail: john.mccallum@ plantandfood.co.nz or richard.macknight@otago. ac.nz. concerning onions grown in controlled environmental conditions have tended to emphasize experimental findings rather than practical details of propagation systems (Brewster, 2008; Khosa et al., 2016). Vigorous and healthy onion plants are a prerequisite for onion physiology and molecular biology research, but this is very difficult to achieve in uncontrolled field conditions. Stressed, suboptimally grown plants can have subtle, and not so subtle, changes in gene expression or plant metabolism that can affect experimental results (Schwarz et al., 2014). A number of excellent reviews have been published for growing Arabidopsis and tomato for experimental purposes, but information is lacking about the cultivation of bulb onion in a laboratory environment (Poorter et al., 2012; Schwarz et al., 2014). Here, we describe practical approaches developed over two decades of growing onions in controlled environmental conditions for physiological and genetic studies.

\section{Reproducibility of Onion Research}

There is increased focus on the reproducibility of research findings in the life sciences
(Baker, 2016). The concern for horticultural science is that although researchers can easily access a growing range of powerful analytical methodologies, such as RNA sequencing, it can be challenging to access common reference seed stocks or practical information concerning propagation methods. We suggest that raising the quality and applicability of and participation in research about orphan crops, such as onion, requires greater sharing of such knowledge. In a related review (McCallum et al., 2018), we describe methodologies for germplasm development, maintenance, and field propagation. In this article, we focus on considerations of genetic variability and strategies for maintaining plant health and reducing variability in controlled environments.

\section{Germplasm selection}

The selection of genetic stocks is one of the greatest challenges facing researchers who wish to address basic questions in onion biology. Locally adapted, open-pollinated (OP) varieties typically harbor considerable heterozygosity (McCallum et al., 2008) and phenotypic variability among plants. Commercial $F_{1}$ hybrids exhibit much greater phenotypic uniformity, but also high heterozygosity, which can complicate molecular analysis. Both OP and hybrid varieties are rarely available long-term, and seedlots of the same variety may differ widely. Whether sourced from commercial suppliers, gene banks, or researchers, seed must be stored in cool conditions in sealed containers over desiccants or in a dedicated cabinet or seed store to prolong viability. Clonal multiplication of single plants is possible through "twin-scaling" methods widely used in bulbing monocots (https://en.wikipedia.org/wiki/ Twin-scaling). Asexually propagated $A$. cepa L. ("true shallot") may be an attractive choice for research purposes in some cases, depending on virus load.

Doubled haploid (DH) lines, most notably those developed at Cornell University, have proven to be highly practical for use both as genetically homogeneous reference lines and for experimental population development (Alan et al., 2004; Baldwin et al., 2014; Lee et al., 2013). We have found these DH lines to be very practical for molecular studies of plant physiology under controlled conditions (Joshi, 2014; Lee et al., 2013; McCallum et al., 2014) due to their uniformity, vigor, and availability.

\section{Plant propagation media}

We have used three contrasting controlled environments and media where we have wished to control plant nutrition and/or temperature and photoperiod for physiological studies. Hydroponic cultivation in heated glasshouses with natural lighting was used for comparative studies of sulfur metabolism (McCallum et al., 2011; Randle et al., 1995). Sand propagation in a controlled-climate facility was used to permit full control over both nutrition and plant development (Joshi, 2014). More recently, we have used 
soil propagation in standard growth rooms for studies of photoperiod bulbing (Lee et al., 2013). Hydroponic culture is laborious, but permits precise control over nutrition and enables collection of root tissues. Sand culture provides similar advantages with simpler setup but is suited to only short-term cultivation experiments. Where plant nutrition management is less critical, the use of standard growing media is preferred. Our research practices using these media for onion propagation are described in the following sections.

Hydroponics. Static solution culture is useful to grow onions for both physiological and genetic studies (McCallum et al., 2002; Randle, 2000) and to provide plant material, such as roots, as a starting substrate for the extraction and characterization of specific enzymes (Lancaster et al., 2000) or gene expression studies.

The culture unit used in these studies consisted of a plastic tub of dimensions $43 \times$ $34 \times 16 \mathrm{~cm}$ that can contain up to $18 \mathrm{~L}$ of nutrient solution. Holes of $2-\mathrm{cm}$ diameter were drilled into the lid dependent on the plant density required. Nine plants could be accommodated if grown through to bulbing or up to 18 plants if harvested as immature "spring onions." A plastic-coated metal frame sat on the lid and supported the foliar canopy growth as the plants developed. The tub was filled with $18 \mathrm{~L}$ of nutrient solution and was aerated continuously with domestic aquarium pumps and sandstone bubblers. An air gap between the top of the solution and the bottom of the lid allowed for solution circulation and for displacement of the solution by expansion of the growing roots.

Seeds were germinated in the dark for $72 \mathrm{~h}$ at $25{ }^{\circ} \mathrm{C}$ on germination paper and transferred to $25-\mathrm{mm}$ cubes of artificial medium (Oasis Horticultural Foam, 9100 LC Thin Cut; Smithers-Oasis, Kent, OH) moistened with distilled water. At the flag leaf stage, the cubes were transferred to the $2-\mathrm{cm}$ holes in the container lid, making sure that the developing roots could reach the nutrient solution. To minimize algal growth, we reduced light by painting tubs black and/or covering with aluminum foil and plugging unused holes in the lid with Oasis blocks. Nutrient solutions were replaced completely every 2 weeks and water levels were maintained daily with deionized water during the 2 weeks.

The nutrient solution composition was based on the "Solution 2" Hoagland solution supplemented with microelements and iron (Hoagland and Arnon, 1950). High-sulfur $(2 \mathrm{~mm}$ with an $\mathrm{N}: \mathrm{S}$ ratio $=7.5)$ and lowsulfur $(50 \mu \mathrm{M}$, with an $\mathrm{N}: \mathrm{S}$ ratio $=300)$ solutions can be prepared from stock solutions as shown in Supplemental Table 1.

Sand. Sand is a useful medium for onion propagation in short-term nutritional studies. In climate laboratory studies (Joshi, 2014), we germinated 'CUDH2107' seed directly in a sand mixture containing 1mm-diameter (K-1 white) sand, 2-mmdiameter (K-2 white) sand, and $<0.3-\mathrm{mm}$
(J61W silica) sand in the ratio 6.6:6.6:1.0. The K-1 and K-2 grade sand was obtained from Industrial Minerals (NZ) Ltd (Auckland, New Zealand) and the J61W silica sand from Industrial Sands, Waikato $\mathrm{Ce}$ ramics (Hamilton, New Zealand). For each pot (Daltons, Auckland, New Zealand), $2 \mathrm{~kg}$ of sand mix was used. Fifteen seeds were germinated per pot in water for $10 \mathrm{~d}$, after which seedlings were thinned to 12 per pot. After $10 \mathrm{~d}$, the plants were watered with their respective $\mathrm{N} / \mathrm{S}$ treatments. In sand culture experiments, we found that because of the low water-holding capacity compared with soil, frequent watering is required. Pots were watered twice daily with a gap of $8 \mathrm{~h}$ in-between. Care needs to be taken that the base of the pot does not form a nutrient gradient owing to accumulation of media in the tray, and therefore trays need to be emptied before each watering.

Soil. Growing media for onion should have good water-holding capacity and aeration. The maintenance of ideal moisture and nutrition in the media is a prerequisite for the healthy growth of onion plants. The frequency of watering depends on the type of media, plant development stage, temperature, and relative humidity maintained in the growth chamber. Keep the soil moist by applying water on a daily basis during germination and on alternate days during later stages of growth, stopping completely at maturity.

For situations in which precise control over nutrition is not required, and it is not necessary to harvest the roots, we use Yates Professional Potting Mix (Yates Orica, Westport, New Zealand). This is sieved to remove coarse particles larger than $2 \mathrm{~mm}$ in diameter, and filled compactly into plastic trays $(15 \times 11 \mathrm{~cm})$. We uniformly broadcast 50 to 100 seeds onto the potting mix and cover them to a depth of 1 to $2 \mathrm{~mm}$ with sieved media. Distilled water is applied with a fine nozzle so as not to disturb the seedbed, and the tray covered with a plastic sheet to prevent moisture loss. We use distilled water because we found that algae grew on the surface of the potting mix when town-supply water was used. Under these conditions, healthy, fresh seeds take, on average, 4 to $5 \mathrm{~d}$ for germination, and soon after germination the plastic sheet was removed. A 25- to 30-day-old seedling with two leaves is ideal for transplanting. The size and color of the pots requires attention for optimum growth of plants under controlled conditions (Poorter et al., 2012). We use light-green-colored pots because the use of dark or black color pots raises the temperature of the substrate and adversely affects plant growth. We transplant two seedlings per pot $(12 \times 15 \mathrm{~cm}$, circa $1 \mathrm{~L})$ for optimum root growth, air, and water distribution. The use of small pots, or more than two seedlings per pot, restricts root growth, which leads to plant stress, and furthermore, high density of onion plants alters light incident on the leaf, which ultimately affects bulbing.

\section{Temperature, humidity, and light}

Most classical physiological research under controlled conditions has focused on regulation of bulb formation. Onions form bulbs in response to daylength, and wide variation between varieties has been observed for bulbing time (Brewster, 2008; McCallum et al., 2014). We have been studying the molecular basis of photoperiodic bulbing in onion and onion's adaptation to a wide range of latitudes. Under field conditions, variability in light intensity and temperature affects the bulbing response and complicates molecular studies. By contrast, uniformity can be easily achieved under controlled conditions for light, temperature, and relative humidity, which increases the precision in gene expression quantification.

For our current studies of adaptive physiology in diverse onion genetics, we have used standard controlled-growth facilities, as typically used for Arabidopsis and other model plants. Filtered, air-conditioned air is pumped in and out of the room, providing good airflow, and maintains a set temperature. We grow onions between 20 and $25^{\circ} \mathrm{C}$, with a relative humidity of $40 \%$ to $50 \%$. High temperature $\left(>30{ }^{\circ} \mathrm{C}\right)$ and low relative humidity $(<30 \%)$ favors an increase in the population of thrips, whereas high humidity $(>70 \%)$ increases the incidence of various fungal and bacterial pathogens. Temperature also influences the onion life cycle, with high temperatures causing early bulbing, and low temperatures (even 15 to $20{ }^{\circ} \mathrm{C}$ ) leading to bolting in tropical onion cultivars. Precise temperature control is therefore especially important when studying different growth phases of onion.

Control of light quantity and quality are critical to manage onion growth and development in controlled environments (Brewster, 2008). Under controlled environments, fluorescent tubes, high-intensity discharge (HID) lamps, and light-emitting diodes (LEDs) are used as sources of light. Model plants, such as Arabidopsis and tomato, complete their life cycle normally under fluorescent tubes or HID lamps; however, these are not sufficient to induce bulbing in onion even under inductive daylength. The addition of far-red light during long days has been shown to reliably induce onion bulbing by Lercari and Deitzer (1987). We have grown Cornell long-day DH 'CUDH2107' seedlings in control growth rooms under white fluorescent lights $(\approx 100$ $\mu \mathrm{mol} / \mathrm{m}^{2} / \mathrm{s}$ ) and subsequently transferred to $\approx 300 \mu \mathrm{mol} / \mathrm{m}^{2} / \mathrm{s}$ supplied by a mix of LED grow lights plus far-red light to initiate the transition to bulbing (https://www.easygrow. co.nz/led-grow-lights/953-6-x-100-watt-cobintegrated-led-growlight.html; http://www. hollandsolutions.co.nz/page.php?Horticultural_ LED). Further, we found that addition of far-red under noninductive short days is not able to induce bulbing in 'CUDH2107' onion plants, but when these plants transfer into inductive long days (16 h light and $8 \mathrm{~h}$ dark), bulbing occurred (Fig. 1). This implies that onions form bulbs only when grown under inductive daylength and optimum light quality (far-red). 


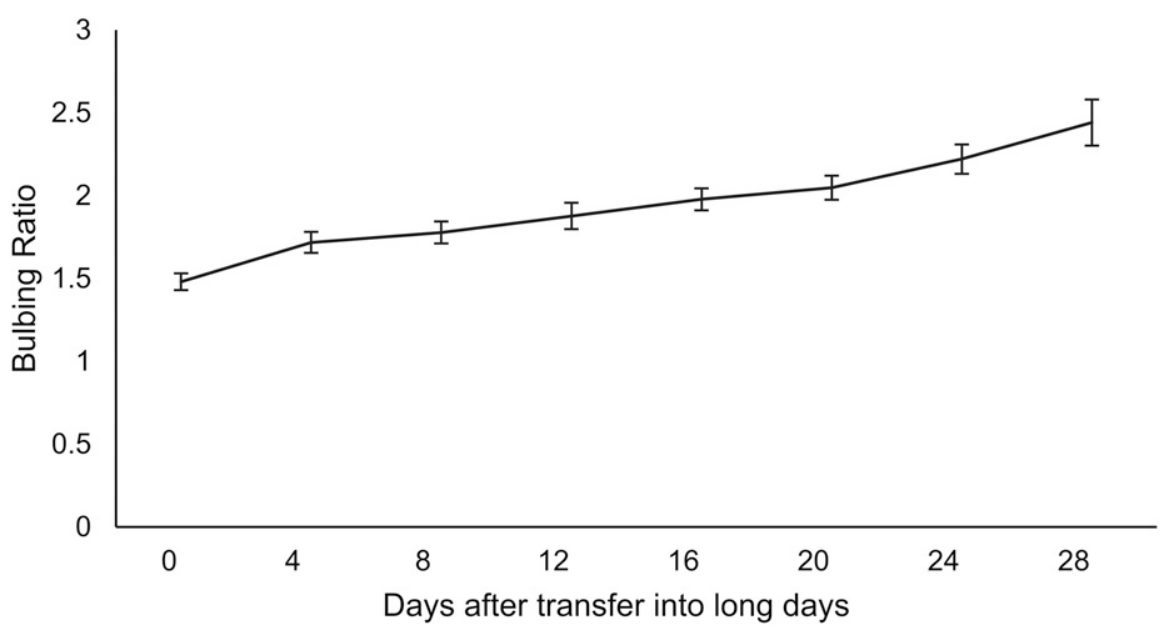

Fig. 1. Bulbing response of reference genotype 'CUDH2107' when shifted to inductive daylength. Plants were grown under short days ( $8 \mathrm{~h}$ light and $16 \mathrm{~h}$ dark) and transferred to long days (LD) (16 h light and $8 \mathrm{~h}$ dark). Data represent an average $( \pm \mathrm{SE})$ of seven replicates.

The effect of red to far-red light ratio (R: FR) was also evident in the climate laboratory sand culture studies, where, after a month of short-day treatment $(10 \mathrm{~h} / 14 \mathrm{~h}$ day/night light, $25^{\circ} \mathrm{C} / 15^{\circ} \mathrm{C}$ day/night temperature) at R:FR of $1: 3$, plants were transferred to longday treatment $(14 \mathrm{~h} / 10 \mathrm{~h}$ day/night $)$ with increased R:FR ratio $(1: 2)$. The lighting within this controlled-environment facility (Warrington et al., 1978; Norling et al., 2003 ) consisted of four 1-kW HID lamps, in combination of six 1-kW tungsten halogen lamps for R:FR of $1: 3$, and twelve 1$\mathrm{kW}$ tungsten halogen lamps for the R:FR of $1: 2$. Bulbing was induced successfully under these conditions, as was evident by change in transcription levels of the bulbing regulator genes FLOWERING LOCUS T1 (AcFT1) and AcFT4 (Lee et al., 2013; Joshi, 2014).

\section{Control of insect pests and diseases}

Most onion experiments under controlled conditions require onion plants to be free from insect pests and diseases. Bulb onion has a long life cycle compared with other model plants, and is often infested by flies, thrips, and fungal pathogens. With proper monitoring and treatment, these insect pests and diseases can be effectively managed. However, the best option to grow healthy onions is to follow good cultural practices in growth rooms and greenhouses.

Researchers should keep the growth area clean before planting onions, and potting mix bags should be kept closed after use to reduce the media drying out and/or sciarid fly infestation. Try to use new pots, or sterilize old pots by washing with $10 \%$ bleach solution followed by rinsing in water. Always place sticky insect traps in the room to both monitor the incidence of insect pests and control them. Growth rooms should be regularly monitored to remove dead or infested plant parts as soon as possible. Once an experiment is finished, the growth room should be cleaned, disinfected, and kept empty for at ion and reduce wasted effort and experimental variability. Greater usage of common methods and genetic stocks will permit onion research to benefit from modern profiling technologies.

\section{Literature Cited}

Alan, A.R., A. Brants, E. Cobb, P.A. Goldschmied, M.A. Mutschler, and E.D. Earle. 2004. Fecund gynogenic lines from onion (Allium cepa $\mathrm{L}$.) breeding materials. Plant Sci. 167:1055-1066.

Baker, M. 2016. 1,500 scientists lift the lid on reproducibility. Nature 533(7604):452-454.

Baldwin, S., R. Revanna, M. Pither-Joyce, M. Shaw, K. Wright, S. Thomson, L. Moya, R. Lee, R. Macknight, and J. McCallum. 2014. Genetic analyses of bolting in bulb onion (Allium cepa L.). Theor. Appl. Genet. 127(3):535-547.

Brewster, J.L. 2008. Onions and other vegetable alliums. CABI, Wallingford, UK.

Hoagland, D.R. and D.I. Arnon. 1950. The waterculture method for growing plants without soil. 2nd ed. Circular 347. California Agricultural Experiment Station, College of Agriculture, University of California, Berkeley, CA.

Joshi, S. 2014. Interaction between sulfur (S) and nitrogen $(\mathrm{N})$ assimilation pathways in response to $\mathrm{S}$ and $\mathrm{N}$ supply in onion (Allium cepa $\mathrm{L}$.). Massey University, Palmerston North, New Zealand, PhD Diss.

Khosa, J.S., J. McCallum, A.S. Dhatt, and R. Macknight. 2016. Enhancing onion breeding using molecular tools. Plant Breed. 135:9-20.

Lancaster, J.E., M.L. Shaw, M.D. Joyce, J.A McCallum, and M.T. McManus. 2000. A novel alliinase from onion roots. Biochemical characterization and cDNA cloning. Plant Physiol. 122(4):1269-1280.

Lee, R., S. Baldwin, F. Kenel, J. McCallum, and R. Macknight. 2013. FLOWERING LOCUS T genes control onion bulb formation and flowering. Nat. Commun. 4:2884.

Lercari, B. and G. Deitzer. 1987. Time-dependent effectiveness of far-red light on the photoperiodic induction of bulb formation in Allium cepa $\mathrm{L}$. Photochem. Photobiol. 45(S1):831-835.

McCallum, J.A., M. Pither-Joyce, and M. Shaw. 2002. Sulfur deprivation and genotype affect gene expression and metabolism of onion roots. J. Amer. Soc. Hort. Sci. 127:583-589.

McCallum, J., S. Thomson, M. Pither-Joyce, F. Kenel, A. Clarke, and M.J. Havey. 2008. Genetic diversity analysis and single-nucleotide polymorphism marker development in cultivated bulb onion based on expressed sequence tag-simple sequence repeat markers. J. Amer. Soc. Hort. Sci. 133:810-818.

McCallum, J., L. Thomas, M. Shaw, M. PitherJoyce, S. Leung, M. Cumming, and M.T. McManus. 2011. Genotypic variation in the sulfur assimilation and metabolism of onion (Allium cepa L.) I. Plant composition and transcript accumulation. Phytochemistry 72(9): 882-887.

McCallum, J., S. Baldwin, S. Thomson, M. PitherJoyce, F. Kenel, R. Lee, J.S. Khosa, and R. Macknight. 2014. Molecular genetics analysis of bulb onion (Allium cepa L.) adaptive physiology. Acta Hort. 1110:71-76.

Onion cultivation under controlled conditions offers better control over environmental factors and use of DHs increases uniformity and reproducibility of experiments. We hope that this practical information concerning choices of germplasm, propagation media, cultivation methods, and environment may encourage greater experimentation with on-
McCallum, J., S. Baldwin, R. Macknight, J. Khosa, and M. Shaw. 2018. Molecular mapping of genes and QTL: progress to date and development of new population resources for NGS genetics, p. 181-196. In: M. Shigyo, A. Khar, and M. Abdelrahman (eds.). The allium genomes. Compendium of Plant Genomes Series. Springer, Cham, Switzerland. 
Norling, C.L., D.H. Greer, H.N. Wiggins, E.A. Halligan, and V.L. Johnson. 2003. Plant growth responses to irradiance patterns under controlled environment conditions. Int. J. Biol. 32:49-63.

Poorter, H., F. Fiorani, M. Stitt, U. Schurr, A. Finck, Y. Gibon, B. Usadel, R. Munns, O.K. Atkin, F. Tardieu, and T.L. Pons. 2012. The art of growing plants for experimental purposes: a practical guide for the plant biologist. Funct. Plant Biol. 39:821-838.
Randle, W.M., J.E. Lancaster, M.L. Shaw, K.H. Sutton, R.L. Hay, and M.L. Bussard. 1995 Quantifying onion flavor compounds responding to sulfur fertility-sulfur increases levels of alk (en) yl cysteine sulfoxides and biosynthetic intermediates. J. Amer. Soc. Hort. Sci. 120:1075-1081.

Randle, W.M. 2000. Increasing nitrogen concentration in hydroponic solutions affects onion flavor and bulb quality. J. Amer. Soc. Hort. Sci. 125:254-259.
Schwarz, D., A.J. Thompson, and H.P. Kläring. 2014. Guidelines to use tomato in experiments with a controlled environment. Front. Plant Sci. 5:625.

Serra, A.-D.B. and L. Currah. 2002. Agronomy of onions, p. 187-232. In: H.D. Rabinowitch and L. Currah (eds.). Allium crop science: recent advances. CABI, Wallingford, UK.

Warrington, I.J., T. Dixon, R.W. Robotham, and D.A. Rook. 1978. Lighting systems in major New Zealand controlled environment facilities. J. Agr. Eng. Res. 23:23-36. 
Supplemental Table 1. Preparation of hydroponic solutions for onion: Individual macroelement stocks at $1 \mathrm{M}, \mathrm{Ca}\left(\mathrm{NO}_{3}\right)_{2} \cdot 4 \mathrm{H}_{2} \mathrm{O}, \mathrm{KNO}_{3}, \mathrm{NH}_{4} \mathrm{H}_{2} \mathrm{PO}_{4}$, $\mathrm{MgSO}_{4} \cdot 7 \mathrm{H}_{2} \mathrm{O}, \mathrm{Mg}\left(\mathrm{NO}_{3}\right)_{2} \cdot 6 \mathrm{H}_{2} \mathrm{O}$; iron supplement Fe-EDTA 6.7g/L; and combined microelements stock solution of $\mathrm{H}_{3} \mathrm{BO}_{3} 2.66 \mathrm{~g} / \mathrm{L}, \mathrm{MnCl}_{2} \cdot 4 \mathrm{H}_{2} \mathrm{O}$ $1.81 \mathrm{~g} / \mathrm{L}, \mathrm{ZnSO}_{4} \cdot 7 \mathrm{H}_{2} \mathrm{O} 0.22 \mathrm{~g} / \mathrm{L}, \mathrm{CuSO}_{4} \cdot 5 \mathrm{H}_{2} \mathrm{O}$ $0.08 \mathrm{~g} / \mathrm{L}$, and $\mathrm{Na}_{2} \mathrm{MoO}_{4} \cdot \mathrm{H}_{2} \mathrm{O} 0.02 \mathrm{~g} / \mathrm{L}$.

\begin{tabular}{lcc}
\hline Stock solution & $\begin{array}{c}\text { High sulfur } \\
(\mathrm{mL} / \text { tub })\end{array}$ & $\begin{array}{c}\text { Low sulfur } \\
(\mathrm{mL} / \mathrm{tub})\end{array}$ \\
\hline $\mathrm{Ca}\left(\mathrm{NO}_{3}\right)_{2} \cdot 4 \mathrm{H}_{2} \mathrm{O}$ & 72 & 36.9 \\
$\mathrm{KNO}_{3}$ & 108 & 108 \\
$\mathrm{NH}_{4} \mathrm{H}_{2} \mathrm{PO}_{4}$ & 18 & 18 \\
$\mathrm{MgSO}_{4} \cdot 7 \mathrm{H}_{2} \mathrm{O}$ & 36 & 0.9 \\
$\mathrm{Mg}\left(\mathrm{NO}_{3}\right)_{2} \cdot 6 \mathrm{H}_{2} \mathrm{O}$ & 0 & 35.1 \\
IRON-EDTA & 18 & 18 \\
Microelements & 7 & 7 \\
Water & 17,741 & 17,776 \\
\hline
\end{tabular}

